\title{
Disease progression in young patients with COPD: rethinking the Fletcher and Peto model
}

\author{
Pablo Sanchez-Salcedo', Miguel Divo², Ciro Casanova ${ }^{3}$, Victor Pinto-Plata², \\ Juan P. de-Torres ${ }^{1}$, Claudia Cote ${ }^{4, t}$, Carlos Cabrera ${ }^{5}$, Jorge Zagaceta ${ }^{1}$, \\ Roberto Rodriguez-Roisin ${ }^{6}$, Javier J. Zulueta', Jose Maria Marin ${ }^{7}$ and \\ Bartolome Celli²
}

Affiliations: ${ }^{1}$ Pulmonary Dept, Clinica Universidad de Navarra, Pamplona, Spain. ${ }^{2}$ Pulmonary and Critical Care Division, Brigham and Women's Hospital, Boston, MA, USA. ${ }^{3}$ Pulmonary Dept, Hospital Universitario La Candelaria, Tenerife, Spain. "Bay Pines VA Health Care System, St Petersburg, FL, USA. ${ }^{5}$ Pulmonary Dept, Hospital Universitario Dr Negrín, Las Palmas de Gran Canaria, Spain. ${ }^{6}$ Pulmonary Dept, Hospital ClínicIDIBAPS-CIBERES, Barcelona, Spain. ${ }^{7}$ Pulmonary Dept, Hospital Miguel Servet, Zaragoza, Spain.

Correspondence: Bartolome Celli, Brigham and Women's Hospital, Pulmonary and Critical Care Division, 75 Francis St, Boston, MA, USA. E-mail: bcelliđapartners.org

ABSTRACT Chronic obstructive pulmonary disease (COPD), although frequent in older individuals, can also occur at younger age; this latter population has not been well described.

We reviewed the functional progression of 1708 patients with COPD attending pulmonary clinics. Those with three or more annual spirometries were divided into those who, at enrolment, were $\leqslant 55(n=103)$ or $\geqslant 65(n=463)$ years of age (younger and older COPD, respectively). Baseline and annual changes in lung function (forced expiratory volume in $1 \mathrm{~s}(\mathrm{FEV} 1)$ ) and BODE (body mass index, airflow obstruction, dyspnoea, exercise capacity) score were recorded and compared between both groups.

Severity distribution by Global Initiative for Chronic Obstructive Lung Disease and BODE scores were similar in both groups, except for mild obstruction, which was higher in the younger group. Mean FEV1 decline was 38.8 and $40.6 \mathrm{~mL} \cdot$ year $^{-1}$, while BODE scores increased 0.19 and 0.23 units per year, for younger and older COPD, respectively. Both groups had similar proportion of FEV1 rapid decliners ( $42 \%$ and $46 \%$, respectively).

The severity distribution and progression of disease in younger patients with COPD is similar to that of patients of older age. This observation suggests that younger individuals presenting with COPD develop the disease from an already compromised pulmonary and systemic status, complementing the model of steeper decline of lung function proposed by Fletcher and Peto.

@ERSpublications

Baseline distribution of COPD severity and disease progression is similar in younger and older patients http://ow.ly/uMKQ5

For editorial comments see page 280 .

Earn CME accreditation by answering questions about this article. You will find these at erj.ersjournals.com/misc/ cmeinfo.xhtml

This article has supplementary material available from erj.ersjournals.com

Received: Nov 292013 | Accepted after revision: March 152014 | First published online: April 22014

Conflict of interest: None declared.

Copyright @ERS 2014 


\section{Introduction}

Chronic obstructive pulmonary disease (COPD) is a major public health problem $[1,2]$ that is projected to become the third cause of mortality worldwide by 2020 [3]. It is characterised by persistent airflow limitation that is thought to be progressive and to be diagnosed late in life, usually in individuals $>65$ years of age [4]. However, COPD can also be diagnosed at much younger age, and the clinical characterisation of this subgroup has not been well established [4-7].

The traditional model of COPD progression was proposed by FLETCHER and PETO [8] more than 30 years ago and describes disease progression as resulting from an accelerated decline in lung function in susceptible subjects, resulting clinical COPD over a period of years. Recent publications have argued against this model, showing that lung function change is heterogeneous, with the minority of patients actually having a rapid decline while many patients manifest nonrapid decline and some even sustain improved lung function over time [5, 9-13]. Most of these studies were based on sample populations with a mean age of 65 years [9-13].

We hypothesised that younger individuals presenting with clinical COPD could provide important information regarding disease progression. To investigate this and as part of the BODE (body mass index, airflow obstruction, dyspnoea, exercise capacity) cohort study of patients attending pulmonary clinics, we have followed over time a large group of younger patients attending clinics because of COPD and compared their progression with that of older patients with COPD followed during the same time, at the same location and by the same personnel.

\section{Methods \\ Subjects}

Subjects were selected from the prospective, multicentre BODE cohort. The details of the inclusion and exclusion criteria have been previously published $[9,14,15]$. In brief, the cohort included sequential patients with COPD who attend pulmonary clinics in Tampa, FL, and Boston, MA, in the USA, and Pamplona, Tenerife and Zaragoza in Spain between November 1997 and October 2011. COPD was diagnosed on the basis of 20 pack-years of smoking history and a post-bronchodilator spirometry showing a forced expiratory volume in $1 \mathrm{~s}(\mathrm{FEV} 1) /$ forced vital capacity ratio $<0.7$ following the American Thoracic Society/European Respiratory Society standards [16]. Values from HANKINSON et al. [17] were used as reference for spirometric measurements for the USA and those from RocA et al. [18] for Spain. Patients were excluded if they had asthma as defined by any of the following: history of asthma, wheeze, or $>200 \mathrm{~mL}$ or $>12 \%$ increase in FEV1 after inhalation of $400 \mu \mathrm{g}$ albuterol. The Global Initiative for Chronic Obstructive Lung Disease (GOLD) 2007 criteria were used for grading the disease severity [19]. The ethics committee at each centre approved the study and all patients gave their informed consent [14].

\section{Variables and follow-up}

Age, and anthropometric and functional parameters were measured at baseline and at each yearly visit, including spirometry, body mass index, distance walked in $6 \mathrm{~min}$ and dyspnoea score on the Modified Medical Research Council scale. The BODE index was also recorded at each visit as previously described [14]. Medications were reviewed and tabulated. Comorbidities were also considered using the Charlson index.

For the current study, we selected those patients aged $\leqslant 55$ and $\geqslant 65$ years at enrolment (younger COPD and older COPD, respectively). In each group, only those individuals who had baseline measurements and at least two visits were considered for analysis (at least three measurements in total). This implied a minimum follow-up of 24 and a maximum of 167 months.

\section{Data analysis}

Disease progression in each age group was assessed by calculating the annual change in their functional parameters. Time series trend analysis was performed to estimate the individual slope of variables using at least three measurements (mean number of spirometries was five). A linear model was used to estimate the slope of the FEV1 decline and BODE index progression. Annual changes in FEV1 were expressed in absolute values (millilitres per year) and as proportions (\% predicted), whereas the BODE index change was expressed as simple variations in units. The annual changes were also compared between the two study groups.

For the assessment of lung function decline, we defined "rapid decliners" as those subjects who had a loss of $\geqslant 40 \mathrm{~mL}$ FEV1 per year, according to ECLIPSE (Evaluation of COPD Longitudinally to Identify Predictive Surrogate End-points) data [8]. Lastly, we stratified the two study groups by GOLD grades and BODE quartiles (quartile 1: 0-2; quartile 2: 3-4; quartile 3: 5-6; quartile 4: 7-10) and compared their baseline characteristics and disease progression. In order to increase the number of individuals with severe disease, we unified GOLD grades 3 and 4 into a single group. 
We used the two-sample t-test when comparing continuous, normally distributed variables between groups. For non-normal variables, we used the Wilcoxon rank test or Chi-square test where appropriate. A p-value of $<0.05$ was considered significant and $95 \%$ confidence intervals are reported when appropriate. All statistical analyses were performed using JMP Pro 10.0 for Windows (SAS Institute Inc., Cary, NC, USA).

\section{Results}

\section{Study population}

From a total of 1708 subjects participating in the BODE cohort during the study period, there were 288 $(17 \%)$ patients $\leqslant 55$ years and $911(53 \%)$ individuals $\geqslant 65$ years of age. From these groups, those with at least three measurements were 103 and 463 patients, respectively (fig. 1). We compared the characteristics of those patients with three or more clinical assessments with that of patients with only two measurements and the results are shown in table E1 of the online supplementary material. The patients were similar in all characteristics, except for the expected shorter follow-up time and fewer clinical assessments in the patients evaluated only twice.

\section{Baseline comparisons}

The baseline characteristics of younger and older COPD are shown in table 1. Although there was a difference in age of $>20$ years between the two groups, there was no difference in lung function at baseline (FEV1 \% predicted) or in distribution of COPD severity between groups, except for GOLD grade 1, which was observed in a larger proportion of patients in the younger population $(p=0.002)$. The proportion of patients on bronchodilators (short- and long-acting) or inhaled long-acting $\beta$-agonists and inhaled corticosteroids was similar in both groups. The older patients showed worse BODE scores and more comorbidities. More patients in the older age group were receiving statins and angiotensin-converting enzyme inhibitors (data not shown). When divided into quartiles, the BODE index was equally distributed in both groups.

\section{Disease progression}

The progression of COPD, whether determined by lung function or BODE index scores, was similar in the two groups (table 1).

\section{Lung function progression}

The distribution of lung function and the mean annual lung function change in millilitres per year showed a similar rate of decline in young and older patients (fig. $2 \mathrm{a}$ and $\mathrm{b}$ ). The mean $\pm \mathrm{SD}$ rate of decline was $38.8 \pm 93 \mathrm{~mL} \cdot$ year $^{-1}$ and $40.6 \pm 96 \mathrm{~mL} \cdot$ year $^{-1}$, respectively $(\mathrm{p}=0.86)$. Similar behaviour was observed if the data were expressed as FEV1 \% predicted $(\mathrm{p}=0.80)$.

The proportion of rapid decliners $\left(\geqslant 40 \mathrm{~mL} \cdot \mathrm{year}^{-1}\right)$ was similar in both groups $(\mathrm{p}=0.41)$. Interestingly, table 2 shows that the pattern of disease progression was similar in younger and older COPD when stratified by baseline GOLD grade. Indeed, figure $2 \mathrm{~b}$ shows that the mean rate of FEV1 decline stratified by baseline GOLD grade was similar in the younger and older COPD subgroups when superimposed on the FLETCHER and PETO [8] graph. The average annual rate of decline between rapid decliners was similar in younger and older COPD $\left(114 \pm 77\right.$ and $117 \pm 66 \mathrm{~mL} \cdot$ year $^{-1}$, respectively; $\left.\mathrm{p}=0.85\right)$ (tables 3 and 4 ).

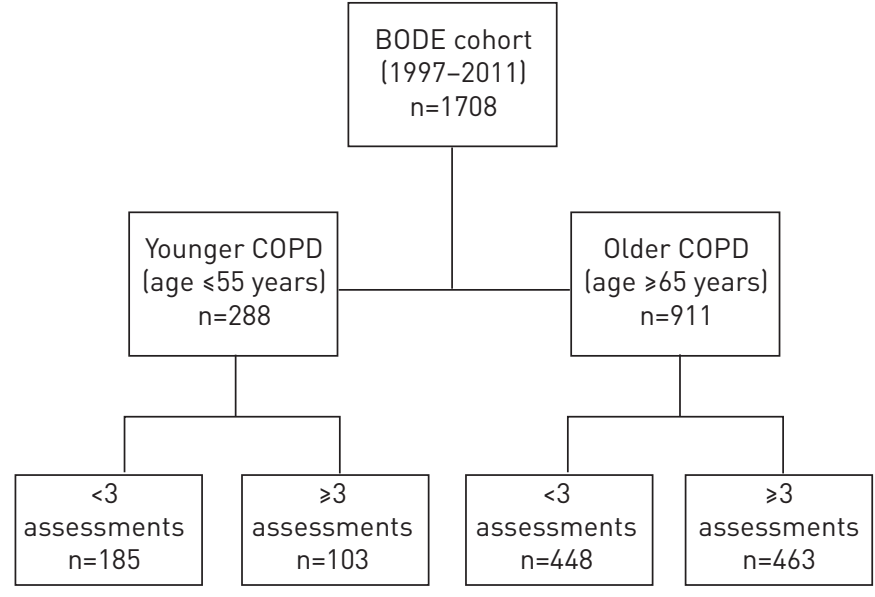

FIGURE 1 Consort diagram showing patient selection from the BODE (body mass index, airflow obstruction, dyspnoea, exercise capacity) cohort. COPD: chronic obstructive pulmonary disease. 
TABLE 1 Baseline characteristics and disease progression in both study groups

\begin{tabular}{|c|c|c|c|}
\hline Variable & Younger COPD & Older COPD & p-value \\
\hline Subjects n & 103 & 463 & \\
\hline \multicolumn{4}{|l|}{ Baseline characteristics } \\
\hline Age years & $50 \pm 4$ & $72 \pm 5$ & \\
\hline Males & $8 \overline{5}$ & $9 \overline{2}$ & 0.02 \\
\hline Follow up months & $62(43-98)$ & $50(36-69)$ & $<0.001$ \\
\hline Survival & 90 & 65 & $<0.001$ \\
\hline Active smoker & 59 & 20 & $<0.001$ \\
\hline FEV $1 \%$ predicted & $53 \pm 24$ & $48 \pm 20$ & 0.06 \\
\hline GOLD 1 & 17.4 & 7.6 & 0.002 \\
\hline GOLD 2 & 28.2 & 35.2 & 0.17 \\
\hline GOLD 3 & 37.9 & 41.0 & 0.55 \\
\hline GOLD 4 & 16.5 & 16.2 & 0.94 \\
\hline Assessments & $4(3-6)$ & $4(3-5)$ & 0.01 \\
\hline Charlson index & $2.3 \pm 1.5$ & $5.0 \pm 2.5$ & $<0.001$ \\
\hline BODE index & $3.4 \pm 2$ & $4.1 \pm 2$ & 0.049 \\
\hline Quartile 1 & $3 \overline{1}$ & $2 \overline{8}$ & 0.55 \\
\hline Quartile 2 & 39 & 30 & 0.13 \\
\hline Quartile 3 & 20 & 25 & 0.32 \\
\hline Quartile 4 & 10 & 17 & 0.14 \\
\hline \multicolumn{4}{|l|}{ Annual change } \\
\hline FEV1 $\mathrm{mL} \cdot \mathrm{year}^{-1}$ & $-38.8 \pm 93$ & $-40.6 \pm 96$ & 0.86 \\
\hline FEV $1 \%$ predicted & $-0.75 \pm 3$ & $-0.66 \pm 3.8$ & 0.80 \\
\hline BODE index & $0.19 \pm 0.5$ & $0.23 \pm 0.6$ & 0.42 \\
\hline Rapid decliners ${ }^{\#}$ & 42 & 46 & 0.41 \\
\hline
\end{tabular}

Data are presented as mean \pm SD, \% or median (interquartile range), unless otherwise stated. COPD: chronic obstructive pulmonary disease; FEV1: forced expiratory volume in $1 \mathrm{~s}$; GOLD: Global Initiative for Chronic Obstructive Lung Disease; BODE: body mass index, airflow obstruction, dyspnoea, exercise capacity. ${ }^{\text {: }}$ FEV1 decline $>40 \mathrm{~mL} \cdot$ year $^{-1}$.

\section{BODE progression}

BODE scores increased (worsened) over time similarly in each age set $(0.19 \pm 0.5$ and $0.23 \pm 0.6$ units per year, $p=0.42$ ) and there was a wide distribution of changes (fig. E1). Mean annual BODE score progression was maintained after stratification by disease severity (table 2). In the younger COPD group, the increase per year was slightly higher in milder COPD grades, in contrast to the older COPD group, where no particular pattern was noticed along the GOLD grades. After stratifying by BODE quartiles, the functional change over time had no particular pattern (table E2).

When each BODE quartile was compared between the two study groups, no significant differences were found in lung function decline rates or in BODE score progression, except in quartile 3, where younger patients had a significantly lower rate of lung function decline $\left(11 \pm 59\right.$ versus $\left.43 \pm 79 \mathrm{~mL} \cdot \mathrm{year}^{-1}, \mathrm{p}=0.03\right)$ and less pronounced progression in BODE score $(-0.1 \pm 0.5$ versus $0.28 \pm 0.7, \mathrm{p}=0.01)$.

\section{Discussion}

This study expands the limited available information regarding young individuals presenting with clinical COPD, not only in their baseline characteristics, but also their progression over time. In this study, $17 \%$ of patients attending clinics were $<55$ years of age and, surprisingly, the clinical expression of the disease, whether evaluated with lung function or multidimensionally with the BODE index, was similar to that of older COPD patients. Furthermore, the progression over time, when stratified by baseline disease severity, was very similar. The similar progression of disease independent of age of diagnosis suggests that the process has developed in individuals with already compromised lung function, and that the idealised baseline takeoff point and subsequent pattern originally described by FleTCHER and PETO [8] may not apply to most patients with COPD attending pulmonary clinics.

Few studies have described the clinical characteristics and progression of individuals diagnosed with COPD at a younger age $[4-7,20]$. HeRsh et al. [6] studied 137 patients with an FEV1 $<40 \%$ predicted who were candidates for lung transplant. However, no description was made of the progression of lung function and there was no comparison with older subjects with the disease. A subsequent cross-sectional study of 2500 

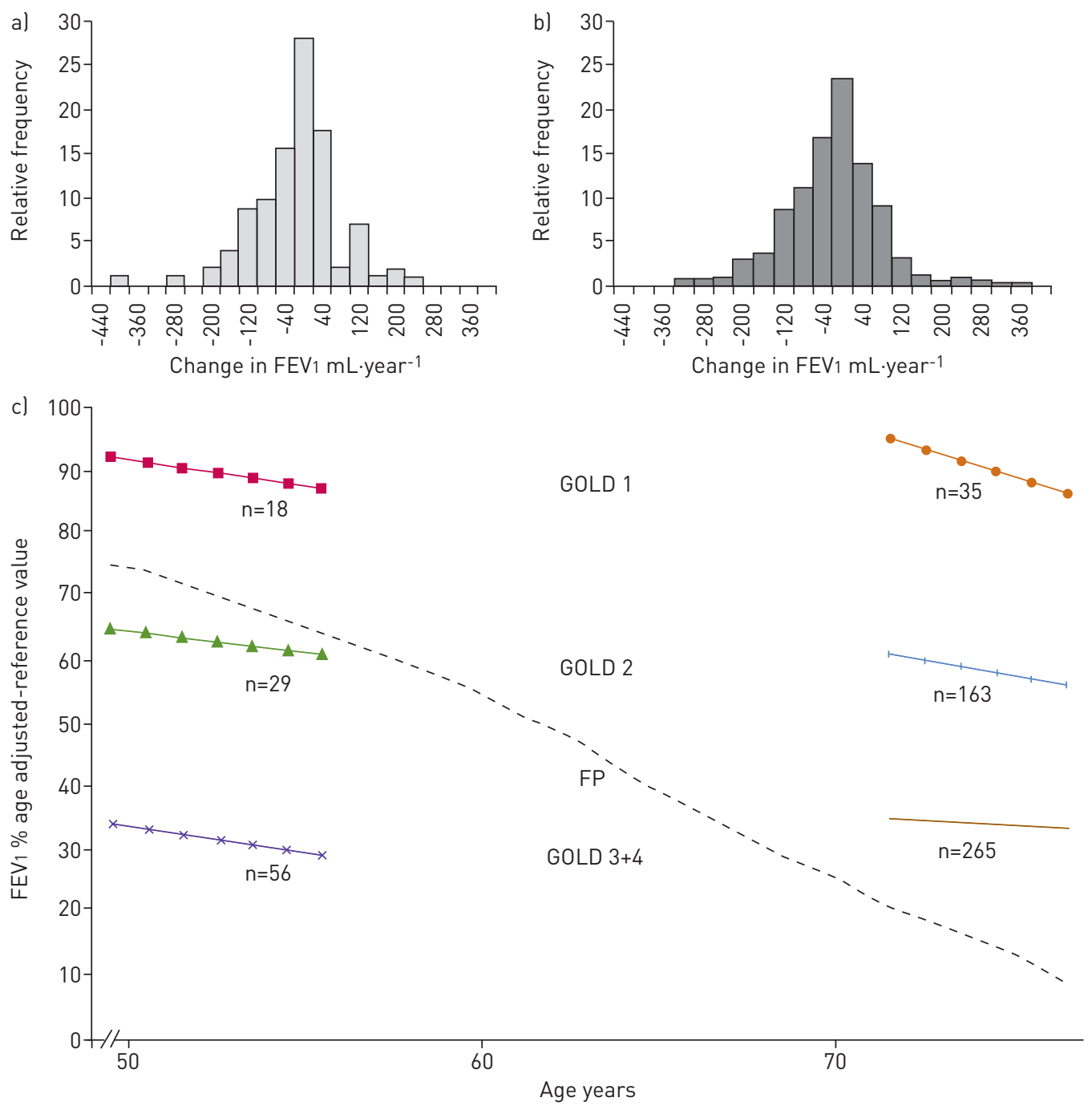

FIGURE 2 Distribution of the mean annual changes in lung function for each study group: a) younger and b) older chronic obstructive pulmonary disease. c) Lung function progression expressed as forced expiratory volume in $1 \mathrm{~s}(\mathrm{FEV} 1)$ $\%$ predicted, stratified by Global Initiative for Chronic Obstructive Lung Disease (GOLD) grades $(1,2$ and $3+4)$ and by age group, compared with the curve from FLETCHER and PETO [8] for smokers (FP).

subjects [4] compared 70 patients with early-onset COPD (FEV1 $<50 \%$ predicted and age $<55$ years) with 306 patients with the same degree of airways obstruction but who were $>64$ years of age, but there was no longitudinal follow-up. A recent report by DRUMmOND et al. [5] of 5885 subjects in the Lung Health Study did evaluate sequential lung function and outcomes in younger patients (49 years). However, the inclusion criteria only considered individuals with mild COPD (FEV1 55-90\% predicted) and 21\% of the subjects did not have COPD. Furthermore, no analysis by individual rate of FEV1 decline was performed. The most important conclusion was that subjects with lower lung function at baseline lost lung function at a steeper rate. Finally, MORICE et al. [7] noted that 356 patients of the $>5800$ enrolled in the UPLIFT (Understanding Potential Long-term Impacts on Function with Tiotropium) study were $<50$ years of age. Although that work did not explore differences in rate of decline between young and older patients, it did show that in patients with COPD, the distribution of airflow obstruction severity by GOLD category was similar irrespective of age. To our knowledge, ours is the first report to compare the progression of disease in younger and older patients encompassing the whole spectrum of mild to very severe COPD.

The fact that the proportion of patients with similar degree of impairment measured by lung function or BODE index is similar in younger or older patients is difficult to reconcile with the FLETCHER and PETO [8] theoretical framework of COPD progression because we would expect that if the individuals started from the same baseline, younger patients would have better lung function than older patients, but this does not occur. An alternative explanation could be selection bias, where the younger patients are seen early and, 
TABLE 2 Baseline functional characteristics and annual changes in younger and older patients classified by baseline Global Initiative for Chronic Obstructive Lung Disease (GOLD) grade

GOLD 1

\begin{tabular}{lll}
\hline $\begin{array}{c}\text { Younger } \\
\text { COPD }\end{array}$ & Older & p-value \\
& COPD &
\end{tabular}

GOLD 2

\begin{tabular}{lll}
\hline $\begin{array}{l}\text { Younger } \\
\text { COPD }\end{array}$ & Older & p-value
\end{tabular}

GOLD 3-4

\begin{tabular}{ccc}
\hline $\begin{array}{c}\text { Younger } \\
\text { COPD }\end{array}$ & Older & p-value \\
& COPD &
\end{tabular}

\begin{tabular}{|c|c|c|c|c|c|c|c|c|c|}
\hline BODE index & $0.5 \pm 1$ & $0.5 \pm 1$ & 0.88 & $1.3 \pm 1$ & $2.5 \pm 2$ & 0.001 & $4.5 \pm 1$ & $5.3 \pm 2$ & 0.01 \\
\hline FEV1 $\mathrm{mL} \cdot$ year $^{-1}$ & $-57 \pm 142$ & $-80 \pm 100$ & 0.27 & $-43 \pm 100$ & $-53 \pm 104$ & 0.32 & $-31 \pm 68$ & $-28 \pm 87$ & 0.39 \\
\hline BODE index & $0.3 \pm 0.6$ & $0.22 \pm 0.4$ & 0.35 & $0.22 \pm 0.3$ & $0.27 \pm 0.6$ & 0.31 & $0.17 \pm 0.5$ & $0.22 \pm 0.6$ & 0.24 \\
\hline
\end{tabular}

Data are presented as mean \pm SD unless otherwise stated. GOLD grades according to the 2007 classification. COPD: chronic obstructive pulmonary disease; FEV1: forced expiratory volume in $1 \mathrm{~s}$; BODE: body mass index, airflow obstruction, dyspnoea, exercise capacity.

thereby, decrease their contribution to the older cohort, because they would die prematurely. However, the findings from the longitudinal follow-up, where younger patients had a lower mortality rate, as shown in table 1, argue against this possibility.

The second and most important contribution of this study is derived from the long-term follow-up (a median of 50 and 62 months for the two groups). As can be seen in table 2, and figure $2 a$ and $b$, the rate of FEV1 decline was almost equal and parallel for both groups at all baseline GOLD grades (fig. 2c). This suggests that the severity of COPD is already established at a young age and that patients maintain their trajectory over time so that the relative position at younger age determines their final position at an older age. Our findings are consistent with the concept that some individuals just do not reach the optimal peak value of FEV1 and may actually have defective lung function to begin with, as was postulated by BURROWs [21] over three decades ago. Some of the factors that have been thought to define altered early lung function include female sex, maternal factors, race and, more importantly, poor airway function in early infancy, which is a known risk factor for lower lung function in young adults [4, 22], which in turn is associated with airway obstruction 20 years later [23]. Our findings are in agreement with this hypothesis and support the need to move upstream for early case detection if we are to prevent ulterior deterioration of lung function.

The third finding is that stratification by GOLD grade revealed that those with a faster rate of decline had milder disease in both age groups. This trend is similar to that of other publications in elderly patients $[9,11,24]$ and different from the "horse-racing effect" described in other studies, whereby those with the most severe FEV1 impairment have faster FEV1 decline $[5,8]$. Our results could be explained by the selection of patients, where the BODE cohort is constituted by patients attending clinics and not evaluated in epidemiological or clinical trials.

Data on the progression of BODE indexes or other functional parameters besides lung function in COPD patients are limited $[9,25,26]$. When stratifying by BODE quartiles, the BODE progression maintained a slow and steady increase. This suggests that the use of multiple dimensions helps smooth the acute variations of individual variables and may provide a better comprehensive evaluation of COPD progression [27].

TABLE 3 Baseline characteristics in younger and older patients according to rapid or nonrapid lung function decline

Younger COPD

\begin{tabular}{lll}
\hline Rapid decliners & $\begin{array}{l}\text { Nonrapid } \\
\text { decliners }\end{array}$ & p-value
\end{tabular}

Older COPD

Rapid decliners $\quad$ Nonrapid $\quad$-value

decliners

\begin{tabular}{lccccc}
\hline Subjects $\mathbf{n}$ & 43 & 60 & & 214 & 249 \\
Age years & $50 \pm 4$ & $50 \pm 4$ & 0.9 & $72 \pm 5$ & $72 \pm 5$ \\
FEV 1 \% predicted & $56 \pm 25$ & $50 \pm 24$ & 0.1 & $52 \pm 21$ & $45 \pm 19$ \\
BODE index & $2.9 \pm 2$ & $3.9 \pm 2$ & 0.03 & $4 \pm 3$ & $4.1 \pm 2$ \\
\hline
\end{tabular}

Data are presented as mean \pm SD unless otherwise stated. COPD: chronic obstructive pulmonary disease; FEV1: forced expiratory volume in $1 \mathrm{~S}$; BODE: body mass index, airflow obstruction, dyspnoea, exercise capacity. 
9 Casanova C, de Torres JP, Aguirre-Jaíme A, et al. The progression of chronic obstructive pulmonary disease is heterogeneous: the experience of the BODE cohort. Am J Respir Crit Care Med 2011; 184: 1015-1021.

10 Tashkin D, Celli B, Senn S, et al. A 4-year trial of tiotropium in chronic obstructive pulmonary disease. $N$ Engl J Med 2008; 359: 1543-1554.

11 Vestbo J, Edwards LD, Scanlon PD, et al. Changes in forced expiratory volume in 1 second over time in COPD. N Engl J Med 2011; 365: 1184-1192.

12 Calverley PMA, Anderson JA, Celli B, et al. Salmeterol and fluticasone propionate and survival in chronic obstructive pulmonary disease. N Engl J Med 2007; 356: 775-789.

13 Nishimura M, Makita H, Nagai K, et al. Annual change in pulmonary function and clinical phenotype in chronic obstructive pulmonary disease. Am J Respir Crit Care Med 2012; 185: 44-52.

14 Celli BR, Cote CG, Marin JM, et al. The body-mass index, airflow obstruction, dyspnea, and exercise capacity index in chronic obstructive pulmonary disease. N Engl J Med 2004; 350: 1005-1012.

15 Divo M, Cote C, de Torres JP, et al. Comorbidities and risk of mortality in patients with chronic obstructive pulmonary disease. Am J Respir Crit Care Med 2012; 186: 155-161.

16 Miller MR, Hankinson J, Brusasco V, et al. Standardisation of spirometry. Eur Respir J 2005; 26: 319-338.

17 Hankinson JL, Odencrantz JR, Fedan KB. Spirometric reference values from a sample of the general U.S. population. Am J Respir Crit Care Med 1999; 159: 179-187.

18 Roca J, Burgos F, Sunyer J, et al. References values for forced spirometry. Eur Respir J 1998; 11: 1354-1362.

19 Rabe KF, Hurd S, Anzueto A, et al. Global strategy for the diagnosis, management, and prevention of chronic obstructive pulmonary disease: GOLD executive summary. Am J Respir Crit Care Med 2007; 176: 532-555.

Decramer M, Cooper CB. Treatment of COPD: the sooner the better? Thorax 2010; 65: 837-841. Burrows B. An overview of obstructive lung diseases. Med Clin North Am 1981; 65: 455-471.

Stern DA, Morgan WJ, Wright AL, et al. Poor airway function in early infancy and lung function by age 22 years: a non-selective longitudinal cohort study. Lancet 2007; 370: 758-764.

23 Kalhan R, Arynchyn A, Colangelo LA, et al. Lung function in young adults predicts airflow obstruction 20 years later. Am J Med 2010; 123: 468

24 Celli BR, Thomas NE, Anderson JA, et al. Effect of pharmacotherapy on rate of decline of lung function in chronic obstructive pulmonary disease: results from the TORCH study. Am J Respir Crit Care Med 2008; 178: 332-338.

25 Casanova C, Cote CG, Marin JM, et al. The 6-min walking distance: long-term follow up in patients with COPD. Eur Respir J 2007; 29: 535-540.

26 Oga T, Nishimura K, Tsukino M, et al. Exercise capacity deterioration in patients with COPD: longitudinal evaluation over 5 years. Chest 2005; 128: 62-69.

27 Casanova C, Aguirre-Jaime A, de Torres JP, et al. Longitudinal assessment in COPD patients: multidimensional variability and outcomes. Eur Respir J 2014; 43: 745-753.

28 Wang ML, Gunel E, Petsonk EL. Design strategies for longitudinal spirometry studies: study duration and measurement frequency. Am J Respir Crit Care Med 2000; 162: 2134-2138. 